\title{
LA FORTALEZA DE CHIPUDE Y LOS CONCHEROS DE ARGUAMUL AL CABO DE TRES DÉCADAS: VIEJOS PROBLEMAS, NUEVAS INTERPRETACIONES
}

\author{
THE CHIPUDE FORTRESS AND THE ARGUAMUL SHELL MIDDEN, THREE \\ DECADES ON. OLD PROBLEMS, NEW INTERPRETATIONS
}

por

\author{
Juan Fco. Navarro Mederos, Cristo M. Hernández Gómez, Ana Barro Rois,

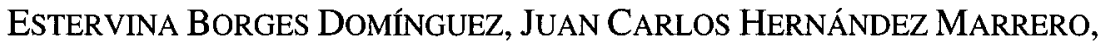 \\ VERÓNICA ALBERTO BARROSO
}

\begin{abstract}
RESUMEN Se expone el estado actual de dos líneas de investigación cuyos yacimientos emblemáticos fueron estudiados por M.Pellicer y P.Acosta. Se contextualiza la Fortaleza de Chipude en el marco de las actuales investigaciones sobre los pireos o aras de sacrificio, y se revisan los resultados de las excavaciones en los Concheros de Arguamul a partir de nuevos enfoques.

ABSTRACT Two current research are exposed from the two archaeological sites digged by M. Pellicel and P. Acosta. We use La Fortaleza de Chipude as an example of emblematic place in the context of the actual research on altars of stones or pyres. Also we review the studies on shell midden at Arguamul from new perspectives.
\end{abstract}

Palabras claves Aras de sacrificio, piras, concheros, arqueología, prácticas sociales, territorio, Islas Canarias.

Key words Pyres, shell midden, archaeology, social practices, territory, Canary Islands.

\section{VOLVER LA VISTA ATRÁS: MANUEL PELLICER Y PILAR ACOSTA EN LA GOMERA}

En 1968 los profesores Pellicer Catalán y Acosta Martínez llegaban a la Universidad de La Laguna en un momento crucial de renovación para la antigua Facultad de Filosofía y Letras, cuando se produjo un insólito incremento en la dotación de profesores y el viejo Seminario de Historia se dividió en diversos Departamentos. A ellos les correspondió crear el de Prehistoria y Arqueología, con lo que nuestra disciplina acabó por integrase al ámbito universitario canario, haciendo posible la formación de especialistas y asegurando la continuidad de un quehacer científico hasta entonces marcado por la irregularidad. 
Durante las tres décadas transcurridas el Departamento ha formado un número elevado de arqueólogos canarios en constante aumento, y se han producido sustanciosos cambios en el ámbito teórico y metodológico, como ha sucedido en el resto del Estado. Hasta los años setenta tuvieron una presencia casi exclusiva las influencias del neopositivismo alemán y la Escuela Histórico-Cultural, pero en el tránsito a los ochenta empezó una transformación y una diversificación de los enfoques. Como es costumbre, el inicio de cada etapa de cambio siempre ha estado acompañado de críticas contra el trabajo de los predecesores, que más tarde tienden a atemperarse cuando los nuevos posicionamientos alcanzan la madurez. Así sucedió en los años de 1970 respecto al periodo de las Comisarías-Delegaciones de Excavaciones y diez años más tarde algunos hicieron lo propio con los inicios del Departamento, hasta que el tiempo puso todo en su lugar.

Nada más llegar a Canarias, Pellicer se esforzó en familiarizarse con la problemática arqueológica del Archipiélago, a través de la producción bibliográfica, los fondos museísticos y los yacimientos conocidos. A partir de ahí diseñó una estrategia de investigación que estaría vigente durante toda la década de 1970, y que en su opinión estaba destinada a poner cierto orden en la arqueología canaria (Pellicer 1969 y 1974). La primera fase fue sistematizar las Cartas Arqueológicas de las Islas para tener una representación objetiva de los datos; a continuación vendrían varios estudios tipológicos de yacimientos y materiales muebles y, paralelamente, excavaciones en sitios de hábitat, con la finalidad de obtener secuencias estratigráficas que dieran una dimensión temporal a la prehistoria y, de paso, reconstruir los modos de vida de las primeras sociedades isleñas. Todo ello lo estructura en Tesinas y Tesis, convirtiéndolo en un proyecto departamental.

De las cinco excavaciones arqueológicas que dirigieron Pellicer y Acosta en Canarias, dos tuvieron lugar en La Gomera: La Fortaleza de Chipude y los Concheros de Arguamul. En este artículo volvemos sobre los pasos de ambos trabajos pioneros, esbozando el desarrollo que han experimentado en estas tres décadas las líneas de investigación que ellos abrieron. Los derroteros han sido muy distintos, mientras La Fortaleza está inmersa en un proyecto de investigación que ha proporcionado un rico panorama interpretativo; los concheros han seguido una suerte desigual, hasta el punto de que aquella vieja excavación continúa siendo prácticamente la mejor referencia.

\section{LA FORTALEZA DE CHIPUDE (Lám I, A)}

En esa planificación general, la Fortaleza de Chipude, probablemente la Argodei ${ }^{1}$ citada en las crónicas, ocupó un destacado lugar, constituyendo una de las primeras intervenciones de la Universidad de La Laguna en el Archipiélago y en concreto la primera excavación que se realizaba en La Gomera. El propio Pellicer se pronunciaba en los siguientes términos: “...me causó honda impresión por su grandeza y por los restos de construcciones que afloraban, cuya función era objeto de debate. ... Y de tal manera me impresionó que desde entonces me comprometí a llevar a cabo su investigación." (Pellicer 1979: 275).

Ningún gomero y probablemente ningún canario permanece impasible ante este emblemático lugar, que impone a propios y extraños por su magnificencia. De hecho, la historia insular testimonia la presencia recurrente de este sitio, que ha pasado a formar parte del ideario colectivo, con distintas implicaciones según las épocas, acabando por convertirse en destacada expresión de la identidad de los gomeros de todos los tiempos.: Estas razones hacen de La Fortaleza un ejemplo paradigmático de vinculación entre Ciencia arqueológica y sociedad, puesto que ambos planos se han visto implicados en un debate que no se mantuvo en los círculos estrictamente académicos, la encendida controversia tuvo su foro de discusión en la producción

1. "Argodei" en lengua gomera significaba "fortaleza" y aunque existen varias, la que más se acerca a la descripción es la de Chipude, situada hacia el SW de la meseta central. Se trata de un domo de forma aproximadamente cilíndrica, con abruptas paredes y plataforma superior plana, de $1243 \mathrm{~m}$ de altitud, a la que sólo puede accederse por un estrecho camino entre rocas. Esta plataforma superior es de planta irregular con un eje mayor de unos $300 \mathrm{~m}$. (Lám I, a). 
científica, pero sobre todo en la prensa diaria. La honda repercusión social de este fenómeno sólo puede entenderse en el marco de las transformaciones políticas por las que estaba atravesando el país en ese momento; con una dictadura que comenzaba a dar claras muestras de cansancio y desarticulación y el impulso que en ciertos sectores de las Islas cobraba un sentimiento nacionalista que hallaba en "lo aborigen" el revulsivo necesario para remarcar la diferencia con el resto del estado español.

El episodio protagonizado por La Fortaleza de Chipude en el proceso de Conquista de la isla propiciaba su percepción como símbolo de "la resistencia de la nación canaria"2. Dicha circunstancia explica que desde muy pronto se incorporara a la lista de yacimientos más citados, a pesar de lo cual su verdadera naturaleza ha sido objeto de polémica no zanjada hasta fechas muy recientes. Esta polémica llegó a polarizarse en torno a las posturas de los que defendían la naturaleza "sagrada" de la montaña y los que se habían decantado por un carácter doméstico.

Las investigaciones se iniciaron en el último tercio del siglo XIX con J. Bethencourt Alfonso, destacado miembro del "Gabinete Científico" de Tenerife, sociedad que, junto con el Museo Canario, de Gran Canaria, promovió la investigación arqueológica en las Islas desde el evolucionismo darwinista. Este investigador, imbuido de un importante componente romántico e indigenista, clasificó en cuatro grupos a las construcciones de piedra seca que estudió en la cima de La Fortaleza. Interpretó dos de ellas como "cabañas" y "corrales"; y a las otras dos como expresión de la religiosidad de los antiguos gomeros: unas aprovechaban concavidades naturales de la roca y opinaba que servirían para libar agua, leche o sangre, mientras que las otras son lo que él mismo denominó "pireos".

Para Bethencourt (1881) allí se daba culto a las "fuerzas de la naturaleza", sacrificando cabritos en los pireos o libando leche, de cuyos ritos se encargarían algunos "magos" que habitarían las cabañas aludidas. Este autor llegó a la conclusión de que estaba en una "Montaña Sagrada", reconociendo las prácticas hierofánicas de la religión gomera y el carácter animista que parecía revestir. El antropólogo francés R. Verneau, muy vinculado a las Sociedades Científicas insulares, ratificaría las conclusiones del investigador tinerfeño.

En los años sesenta del siglo XX se revitalizó el tema, cuando Herbert Nowak ${ }^{3}$ retomó las hipótesis decimonónicas a través de la obra de $\mathrm{R}$. Verneau, abriendo una viva polémica con sus radicales afirmaciones. Este hecho coincide con una fase clave en la investigación sobre la Prehistoria de Canarias, en la que se abogaba decididamente desde el recién creado Departamento de Arqueología y Prehistoria por la profesionalización de la Arqueología, vinculando su práctica a la Universidad, lo que en parte explica el encone de la discusión abierta. Nowak visitó La Fortaleza y escribió varios artículos en periódicos y revistas (Nowak 1967, 1969 y 1975), en los que afirmaba desde perspectivas hiperdifusionistas que ese sitio constituía un ejemplo más de la cultura megalítica anciano-mediterránea del III-II milenio a.n.e. Respondió Elías Serra (1967), Catedrático de Historia de la Universidad de La Laguna, tachando a Nowak de sensacionalista y afirmando que poco habría que añadir a las conclusiones originales de Bethencourt.

Con la intención de que un estudio sistemático ayudara a erradicar la polémica, M. Pellicer excavó en La Fortaleza en $1973^{4}$, publicando un avance en la prensa (Pellicer 1973) y luego presentó algunos resultados preliminares (Pellicer 1979). Esa excavación encajaba muy bien en los planes generales de intervención en el Archipiélago diseñados por él, incorporando a los intereses universitarios la Prehistoria de La Gomera como objeto de investigación.

2. En 1424 o 1425 desembarcó en La Gomera una expedición de conquista capitaneada por Fernando de Castro. Tras una primera escaramuza con un grupo de indígenas, la tropa se internó en la isla, hasta que fueron atacados por el jefe Amaluige y sus guerreros, obligándoles a replegarse hacía Argodei, donde quedaron sitiados.

3. Miembro destacado del Institutum Canarium, asociación austríaca de aficionados a la historia y la arqueología de Canarias y Sahara, creado para acoger el legado del lingüista e historiador Dominik Joseph Wölfel y continuar su obra.

4. Se aprovechó la circunstancia para visitar los pocos yacimientos conocidos hasta entonces y formarse una imagen global de la arqueología gomera. 
En el mencionado trabajo ${ }^{5}$, apoyándose en las características de las estructuras y en el contenido ergológico de algunas de ellas, llegó a conclusiones opuestas a la de los autores citados y cuestionó con firmeza el carácter "sagrado" que hasta entonces se le había otorgado a La Fortaleza. Por el contrario, confería una función doméstica a las numerosas construcciones de la cima, asociándolas al pastoreo como única actividad para la que La Fortaleza tenía, según él, condiciones propicias. La excavación afectó a 24 unidades que clasificó en seis grupos, atendiendo realmente a criterios tipológicos de carácter empírico: cabañas circulares, rediles, conjuntos cabaña-redil, cabañas-abrigo, abrigos y finalmente hogares (los pireos de Bethencourt). Esta interpretación se enmarca en la idea muy en boga entonces de que la recurrencia al mundo "mágicoreligioso" es una explicación demasiado fácil para manifestaciones arqueológicas de difícil interpretación. Desde el departamento universitario, todos sus miembros apoyaron las conclusiones expuestas por Pellicer.

Salvando la Memoria de Licenciatura y otros trabajos de J.F. Navarro, durante la década de los setenta y los ochenta ṇo logró cristalizar una investigación continuada y de equipo en La Gomera. Mientras, la Arqueología en Canarias vivía una renovación, más metodológica que conceptual, de la que sí que se benefició la isla. A su amparo fueron madurándose muchos datos recabados en aquellos trabajos iniciales, cuyo fruto es la primera síntesis global (Navarro 1992). En esta obra se sistematizan las hipótesis que marcarían la investigación actual, revitalizada desde mediados de los noventa. Esta vez el trabajo será obra de un equipo cuyo objetivo de investigación genérico es la explicación de la sociedad como "totalidad histórica concreta" en un marco de análisis de carácter insular.

Todo este periodo supone un punto de inflexión en la concepción que se tiene de La Fortaleza, cuyas razones hay que buscarlas fuera y dentro de la isla. Por una parte, los postulados historicistas pierden vigencia a favor de otras posiciones derivadas de modelos antropológicos y ecológicos, más favorables a las interpretaciones de carácter religioso. Entre algunos investigadores canarios comenzó a fraguar una visión de la cultura como sistema, donde la religión se entendía como un importante subsistema de referencia básica (González y Tejera 1981). En este ambiente, se produjo el hallazgo de otras estructuras semejante en La Gomera $^{6}$ y la excavación de aras de sacrificio en El Hierro (Hernández 1982; Lorenzo 1982). La contextualización de La Fortaleza en el territorio insular será entonces un argumento de peso que hace tambalear esquemas muy asentados. Por vez primera, desde la Universidad se plantea una posible ambivalencia para este conjunto arqueológico ${ }^{7}$, combinando la función doméstica y la ritual, que no se excluyen necesariamente.

El tema será objeto de tratamiento monográfico en un proyecto de investigación que abordamos desde 1994 bajo el título de "Garajonay: Arqueología de las Montañas" y con el que se pretende profundizar en esta línea de estudio. Resulta fundamental entender que las manifestaciones "religiosas" también constituyen para nosotros un objeto de trabajo, son componentes materiales que junto a otros, completan el cuadro fenoménico de una sociedad, pero no definen sus contenidos fundamentales, aunque sí los reflejan. Por tanto, este proyecto forma parte de la arqueología de las prácticas sociales, persiguiendo como finalidad última la explicación de la sociedad gomera prehistórica y no la "religión de los gomeros".

5. La excavación en La Fortaleza y las restantes primeras intervenciones del Departamento, supusieron incorporar a Canarias prácticas de campo como los levantamientos topográficos, el dibujo arqueológico preciso, el tamizado de los sedimentos y la localización espacial de las estructuras, fundamental para el estudio de este tipo de yacimientos. Pellicer advirtió con claridad la importancia que tenía la distribución de los distintos componentes en el contexto espacial.

6. En distintas zonas del centro de la isla hay construcciones similares a la que Pellicer interpretaba como hogares, pero en ámbitos de montaña fuera de los espacios domésticos. Pero el conjunto que más pesó en el vuelco interpretativo que se comenta lo constituye el localizado en el Garajonay, centro y cúspide de La Gomera (Navarro 1992).

7. Si bien es verdad que esta ambivalencia fue levemente sugerida por el propio Pellicer al señalar que: "Dado lo rudimentario de sus construcciones, el lugar con la particularidad de su inexpugnabilidad, sería punto de refugio en caso de peligro, como hemos visto en las fuentes de la conquista, aunque no descartamos la posibilidad de que en ciertas ocasiones pudiera servir de lugar de reunión, como el Garajonay, por motivos políticos, militares e incluso religiosos" (Pellicer 1979: 282). 
Se parte de una concepción materialista histórica, según la cual la formación económico-social no es una suma de piezas, ni la adición de lo material y lo espiritual, sino que "refleja el hecho de que la base material y la superestructura integran la indisoluble unidad real de la sociedad, permitiendo la explicación de su dinámica organicidad en términos de una causalidad múltiple, recíproca yjerarquizada" (Bate 1998: 57).

Las prospecciones sistemáticas realizadas en el marco del proyecto permitieron localizar 56 conjuntos de pireos o aras en un territorio insular de $353.20 \mathrm{~km}^{2}$ (Fig. 1), algunos de los cuales integran más de veinte estructuras. El primer factor clave a destacar es, por tanto, la dimensión insular del fenómeno estudiado, evidenciando un fuerte grado de interrelación en un sistema jerarquizado, susceptible de aportar conclusiones muy significativas en la caracterización de la sociedad gomera prehistórica. Precisamente la identificación de este sistema y sus pautas, con unas características concretas, es el argumento más contundente que ha permitido reconocer en estas estructuras una función ritual como "aras de sacrificio" (Lám. I, b) y, por tanto, decantarnos por el carácter de "Montaña Sagrada" para La Fortaleza y otras elevaciones similares en la isla como El Calvario (Alajeró) o el propio Garajonay (Vallehermoso) ${ }^{9}$. Organizando la información de lo particular a lo general, tres son los elementos discriminantes básicos para ello: el registro material y arqueosedimentario, la organización de los conjuntos y sus características estructurales y el patrón de localización en el territorio. Analizados los tres en conjunto permiten señalar que todo el sistema funciona como un "instrumento sancionador" que refleja en el territorio el modelo de organización social.

En los pireos excavados en el marco del proyecto se da una constante reiteración en el contenido material y sus características, coincidiendo con lo observado en el material de superficie de otros yacimientos. En torno a estas construcciones, entre otras posibles prácticas, se llevó a cabo el sacrificio de animales domésticos del grupo de los ovicaprinos, es decir, los protagonistas mayoritarios de la cabaña ganadera de los antiguos gomeros ${ }^{10}$. Dominan los individuos infantiles y juveniles, aunque también se constatan ejemplares adultos. En ellos se reconoce una peculiar representación anatómica, destacando rotundamente los huesos de las patas y el cráneo, aspecto que evidencia la selección de unas partes muy concretas de determinados animales. Estos restos muestran un elevado índice de termoalteración, indicando que en dichos recintos se producía la cremación recurrente de ciertas porciones animales, en sucesivas reutilizaciones ${ }^{11}$.

La fauna responde, por su composición y manipulación, a un conjunto característico de ofrenda, en la que el fuego cumple un papel primordial. No en vano el pireo $o$ ara de sacrificio es una estructura de combustión en el sentido más básico del término, que se ubica en un lugar preciso, se utiliza en reiteradas ocasiones y se reconstruye tantas veces como sea necesario. El tipo de registro fáunico de las aras difiere de los representados en los contextos de habitación, tanto por la selección de las regiones esqueléticas como por el tratamiento al que son sometidas. No obstante, en un análisis global, tan significativos resultan los repertorios óseos presentes como aquellos otros elementos ausentes, y que indefectiblemente se generan en el sacrificio y procesado de los animales, manifestándose como un trascendente signo de interrelación que permite vincular los contextos rituales a los domésticos; siendo la producción el elemento "esencial" o de vinculación, materializada a través del aprovechamiento socioeconómico de los animales ${ }^{12}$.

8. Consideramos que la esfera espiritual de un colectivo organizado constituye una buena vía de análisis para ahondar en esa organización social, sobre todo teniendo en cuenta que dicha esfera es un producto de la sociedad en el sentido dialéctico de esta expresión. Su función es, por tanto, una función social que reglamenta, normaliza y legitima las relaciones sociales de producción.

9. No obstante, éste no es un fenómeno de montaña, como indican los datos que se adjuntan en este trabajo.

10. Las tercera especie es el cerdo, siempre minoritario.

11. Las afecciones se manifiestan sobre todo en la alteración cromática y en la fracturación del hueso, con un patrón de fragmentación constante. Ambas características permiten determinar la exposición de los animales a un fuego de notable intensidad en el que se adquieren temperaturas superiores a los $200-250^{\circ} \mathrm{C}$, sin que excedieran los $800^{\circ} \mathrm{C}$.

12. Verdaderamente, la evidencia más clara de esta interrelación es la presencia de conjuntos de aras de sacrificio cercanos y relacionados con espacios domésticos, frente a los grandes santuarios cuya función parece tener un alcance más general, como se verá posteriormente. 
La relación entre producción y aras de sacrificio se extiende a otras parcelas, observándose una asociación casi permanente entre la producción lítica y las aras, cuyo ejemplo más ilustrativo es El Piquillo (San Sebastián), que contiene una cantera-taller (Navarro et al. 2000). Los materiales líticos de estos conjuntos no son elementos de ofrenda, sino instrumentos de trabajo que intervienen en la acción ritual. Pero en algunos enclaves, como el citado Piquillo, la producción podría tener un carácter excedentario y estaría dirigida, probablemente, al suministro de las comunidades locales. El resto de las evidencias ergológicas suele ser muy escaso y, cuando aparecen, muestran un menor grado de vinculación con las estructuras rituales propiamente dichas.

Se ha insistido en la dimensión insular de este tipo de manifestaciones, si bien es cierto que dominan en la vertiente meridional, e igualmente se ha hecho hincapié en la diversidad de características que presentan, con conjuntos de muy desigual nivel ${ }^{13}$. Sin embargo, las ubicaciones, así sea cima de montañas, lomadas, crestas o cualquier otra, participan de una serie de cualidades comunes que deben actuar como requisitos en la elección de los emplazamientos. Se buscó la elevación, la verticalidad (Lám. I, B), y en otro orden de cosas, el dominio visual y la intervisibilidad. Estos rasgos son el reflejo de un sistema ideológico unitario de toda la sociedad gomera, y permiten reconocer un entramado de relaciones sociales, cuyo diseño se expresa mediante una red insular de conexiones territoriales. La configuración y consolidación de esta red debió tener lugar en un espectro temporal dilatado paralelo a la socialización de la isla. En consecuencia, un estudio diacrónico del fenómeno permitiría conocer el proceso de construcción del territorio como espacio socializado, en el que el sistema debió mantener larga vigencia ${ }^{14}$.

Los textos etnohistóricos describen una sociedad no igualitaria dividida en varias entidades políticas, donde las relaciones sociales eran de base parental. No obstante, mantenían cierta cohesión, refrendada por mitos que explicaban un proceso de segmentación desde un origen común y legitimaban la organización social del proceso productivo. El sistema de relaciones entre yacimientos es reflejo de este proceso, y así se entiende el destacado papel del bando de Orone (SO de la isla), como territorio del linaje decano que mantiene cierta posición de preeminencia respecto a los restantes bandos, lo que justifica que concentre los grandes santuarios de la isla.

De acuerdo a esta hipótesis, ¿cuál sería el papel de La Fortaleza de Chipude? ¿cabe mantener el carácter singular que se le ha otorgado, o por el contrario su cometido habría que buscarlo en la función que desempeña dentro del sistema de relaciones existentes? La Fortaleza, tiene sus paralelos más evidentes en otros enclaves como el conjunto mixto de montaña de El Calvario (Alajeró) y la alineación Ajojar-Teguerguenche (Vallehermoso). Se trata de hitos destacados en el paisaje que suelen contener un número muy elevado de aras, manifestando especiales condiciones de visualidad y visibilidad respecto a buena parte de la isla. Presiden en su entorno inmediato espacios de claro contenido simbólico, con grandes necrópolis y manifestaciones rupestres, y encabezan territorios de comunidades extensas, en los que se concentran otros conjuntos de aras de rango inferior.

Este grupo se diferencia claramente tanto de los ubicados en la zona cumbrera de la Isla, como de los insertos en los ámbitos de poblamiento estable. En la cumbre, el Garajonay se presenta como un gran santuario, alejado de cualquier asentamiento humano y probablemente dotado de un rango insular. Resulta muy probable

13. Se ha establecido una clasificación sobre la base de las características tipológicas y tipométricas de las estructuras y las asociaciones entre ellas; distinguiendo en un primer estadio entre aras simples y complejas y, en un segundo grado, entre aras simples individuales, conjuntos de aras simples y conjuntos mixtos (de montaña o formando alineaciones en crestas). Una descripción detallada de estas características puede encontrarse en J.F. Navarro et al.( 2001).

14. Una de las estructuras excavadas en La Fortaleza (cuadrícula D/11) se fechó por C-14 en el 470 \pm 60 d.n.e. (Pellicer 1979: 281), aunque su excavador no duda que el yacimiento se inició antes y se mantuvo largamente hasta la conquista. Un documento inédito describe que hasta el s. XVIII se realizaban actos paganos en La Fortaleza. 
que similar alcance cumpliesen otros enclaves también muy prominentes, con marcadas connotaciones hierofánicas, existentes en el sector centro-oriental de esta misma franja, entre los que destacan los Roques de Agando y La Zarcita y otras montañas, confiriendo a la zona más alta de la isla un cometido común, reconocido por la colectividad.

Por debajo del grupo en el que se integra La Fortaleza, se inscriben la mayor parte de los conjuntos, normalmente ubicados sobre lomos, cuchillos y roques que sobresalen en el paisaje inmediato (Mña. de Iguala, Los Picachos, Los Guros, El Higueral), con una explícita relación de intervisibilidad respecto a los grandes santuarios. Desde estos sitios se controla directamente un espacio geográfico muy concreto, generalmente una cuenca de barranco, que podría corresponder al territorio propio de una agrupación local de parentesco. Habría que añadir un reducido número de conjuntos de aras simples ubicados en unidades de acogida de menor entidad y que, como el anterior, tiene también un marcado carácter local. En este caso, las relaciones de intervisibilidad, cuando las hay, se establecen sólo con uno o dos yacimientos vecinos, de esta misma naturaleza.

De todo ello conviene destacar, en primer lugar, un sistema cuya organización sólo se reconoce a escala insular, puesto que halla en la isla su definición completa, como producto y reflejo de una formación social cuyo territorio históricamente significativo es la propia isla. Esta dimensión insular se remarca en El Garajonay y los otros enclaves cumbreros del centro de la isla, donde sólo existen este tipo de yacimientos, que configuran una unidad y están "aislados" del resto de los conjuntos por una franja de territorio circundante, en la que no hay aras. Tal hecho es básico a la hora de interpretar la función de la zona alta de La Gomera, porque si se asume que el sistema de aras forma parte de los mecanismos legitimadores de una determinada organización social, ello equivale a admitir que este proceso en la cumbre adquiere una dimensión global. En segundo lugar, la organización de la producción a escala doméstica tiene su refrendo en una parte esencial de la red identificada, esto es en los conjuntos de aras que se integran en las zonas de poblamiento estable.

El grupo intermedio, entre los que La Fortaleza es el ejemplo paradigmático, tiene un papel articulador clave como mediador entre lo estrictamente local y lo insular. Su radio de influencia abarca a agrupaciones extensas, de carácter parental, participa de las características de los conjuntos de cumbre en cuanto a la complejidad de su organización, la espectacularidad de la unidad de acogida, la no vinculación directa con las áreas de hábitat; pero muestra la particularidad de su más que evidente relación con estas áreas a partir de la red de conexiones que establecen, precisamente, con los conjuntos de rango inferior.

\section{LOS CONCHEROS DE ARGUAMUL}

Meses después de la excavación en la Fortaleza, uno de nosotros empezó su Tesina sobre la Carta Arqueológica de La Gomera (Navarro 1975) y una de las consecuencias primeras fue la localización de numerosos concheros. Este tipo de yacimiento había sido comparado con concheros norteafricanos de supuesta atribución neolítica y, a partir de eso, se habían vinculado a un presunto primer poblamiento de las Islas protagonizado por gentes neolíticas o, al menos de marcados arcaísmos, idea que había calado hondo. Pero ya entonces Pellicer (1974: 146) desconfiaba de que los concheros tuvieran un valor como indicador cronocultural, habida cuenta de su larga perduración en el Continente y en las propias Islas. Todas esas consideraciones carecían de una base empírica sólida, porque hasta entonces sólo se habían realizado dos elementales excavaciones, una en los Concheros de Teno (Tenerife) (Serra 1945 y 1946), y otra por las mismas fechas en los de Punta Llana (La Gomera) (Álvarez 1947), ambas con escasos resultados.

En 1974 localizábamos los Concheros de Arguamul, uno de los cuales estaba desapareciendo por causa de la erosión marina, lo que aconsejaba una excavación de urgencia que permitiese hallar respuesta a algunas 
de las incógnitas que existían sobre este tipo de yacimientos. La intervención tuvo lugar en noviembre de ese año dirigida por P.Acosta (Acosta, Hernández y Navarro 1977) ${ }^{15}$.

El conjunto lo forman dos concheros separados por $10 \mathrm{~m}$, de los que al occidental se denominó 1 y al oriental 2. El primero de ellos debió tener una gran extensión, pero en aquel momento sólo se conservaba una porción de su periferia, porque el mar había ido socavando el cantil sobre el que se asentaba. Su paquete sedimentario era muy uniforme, integrado por una masa tupida de conchas entre las que se intercala escaso sedimento, pero aún así se distinguieron dos niveles parcialmente separados por los restos de una estructura de combustión, consistente en una fina capa de carbones y cenizas. El nivel I tenía un espesor máximo de $15 \mathrm{~cm}$, y el II alcanzaba $17 \mathrm{~cm}$ siendo datado por C-14 en el $1670 \pm 60$ d.C. (CSIC-262)

En el conchero oriental $\left(\mathrm{n}^{\circ} 2\right)$ se distinguieron otros dos niveles de composición similar, pero divididos enteramente por una extensa aunque delgada capa de sedimento rico en materia orgánica. El nivel I alcanzó $25 \mathrm{~cm}$ de espesor mientras que el II tenía una amplitud media de $20 \mathrm{~cm}$ y fue datado por C-14 en el $1530 \pm$ 60 d.C. (CSIC-263).

Los concheros de las Canarias Occidentales, y entre ellos los de La Gomera, suelen presentar una gran homogeneidad en cuanto a los moluscos que los componen, que son siempre un reducido espectro de gasterópodos del piso mesolitoral.Es decir, aquellas especies de interés nutricional a las que tenían acceso, la mayoría propias de la franja intermareal y alguna de la zona bañada por las salpicaduras. Predomina el género de las lapas (Patella) y siguen los burgados (Osilinus atratus) y la púrpura o burgado macho (Thais haemastoma), apareciendo de manera esporádica otros moluscos como Haliotis, Litorina, Columbella, Thericium, Cypraea, Conus, etc.

En las tablas que siguen señalamos los porcentajes en que están representadas las diferentes especies en los Concheros de Arguamul, y que constituye una revisión de lo que en su día fue publicado (P.Acosta et al. 1977: 262-265; J.F. Navarro 1992: 74):

\begin{tabular}{|c|c|c|c|c|c|c|}
\hline $\begin{array}{c}\text { Arguamul } \\
\text { CONCHERO 1 }\end{array}$ & $\begin{array}{c}\text { Patella tenuis } \\
\text { crenata }\end{array}$ & $\begin{array}{c}\text { P. ulyssiponensis } \\
\text { aspera }\end{array}$ & P. piperata & $\begin{array}{c}\text { Thais } \\
\text { haemastoma }\end{array}$ & $\begin{array}{c}\text { Osilinus } \\
\text { atratus }\end{array}$ & otras \\
\hline Nivel I & $51^{\prime} 1 \%$ & $22^{\prime} 2 \%$ & $6^{\prime} 5 \%$ & $13^{\prime} 5 \%$ & $5^{\prime} 5 \%$ & $1^{\prime} 1 \%$ \\
\hline Nivel II (1670 \pm 60 d.C.) & $40^{\prime} 7 \%$ & $10^{\prime} 1 \%$ & $6^{\prime} 7 \%$ & $25^{\prime} 4 \%$ & $17^{\prime} 1 \%$ & \\
\hline $\begin{array}{c}\text { Arguamul } \\
\text { CONCHERO 2 }\end{array}$ & $\begin{array}{c}\text { Patella tenuis } \\
\text { crenata }\end{array}$ & $\begin{array}{c}\text { P. ulyssiponensis } \\
\text { aspera }\end{array}$ & P. piperata & $\begin{array}{c}\text { Thais } \\
\text { haemastoma }\end{array}$ & $\begin{array}{c}\text { Osilinus } \\
\text { atratus }\end{array}$ & otras \\
\hline Nivel I & $52^{\prime} 2 \%$ & $38^{\prime} 4 \%$ & $10^{\prime} 2 \%$ & $6^{\prime} 7 \%$ & $1^{\prime} 5 \%$ & \\
\hline Nivel II (1530 \pm 60 d.C.) & $48^{\prime} 0 \%$ & $20^{\prime} 0 \%$ & $14^{\prime} 0 \%$ & $10^{\prime} 0 \%$ & $8^{\prime} 0 \%$ & \\
\hline
\end{tabular}

Las fechas que suministra el C-14, lejos de resolver problemas, los incrementan. La primera observación es que son muy recientes y, en todo caso, posteriores a la colonización europea, pero están asociadas a cerámicas y utillaje lítico prehistórico. Tal problema se ha intentado explicar de dos maneras: pudiera ser que estén rejuvenecidas por agentes contaminantes, al tratarse de yacimientos al aire libre, o también por contingencias del procesado; pero no descartamos que las dataciones se aproximen a la realidad y que evidencien comportamientos y modos de vida aborígenes durante al menos dos siglos tras la colonización. Esto concuerda con nuestra opinión de que en amplias zonas de esta isla la población indígena mantuvo después de la conquista gran parte de sus hábitos, sobre todo en la medida en que pervivieron fórmulas

15. Seguro que los profs. Pilar Acosta y Mauro Hernández coincidirán en que supuso una irrepetible experiencia profesional y personal, en la que no faltaron incluso fenómenos que deleitarían a los guionistas de "Expediente X". 
semiadulteradas de su antiguo modelo económico y porque los agentes aculturadores tuvieron poca efectividad hasta el siglo XVII.

Otra inferencia que extraemos de esas cronologías es que el conchero 1 es algo más reciente que el 2 , aunque entre el comienzo de uno y otro sólo median $140 \pm 60$ años, lapso tan corto que no permite asegurar ni excluir la posibilidad de que en algún momento llegaran a coexistir.

Es interesante comprobar cómo se produjo en ambos concheros una peculiar evolución en los porcentajes de especímenes de los moluscos. Siempre disminuyen en altura las conchas de Thais y Osilinus, si bien no estamos seguros si se debe a un problema de conservación diferencial de estos caparazones más frágiles, sobre todo teniendo en cuenta que el tracto superior de los concheros ha estado expuesto en tiempos recientes al tránsito de personas. Las dos especies dominantes son la lapa de pie negro ( $P$. tenuis crenata) y la de pie blanco ( $P$. ulyssiponensis aspera) y, aunque siempre abunda más la primera, el incremento que sufre la segunda es porcentualmente mayor en ambos concheros, ya que su presencia se duplica de un nivel a otro. Además, se observa que la talla media de los ejemplares recolectados fue disminuyendo paulatinamente, lo cual debe relacionarse con la presión a que estuvieron sometidas las poblaciones de moluscos. Esas mismas tendencias evolutivas en la composición específica y en las tallas de los ejemplares capturados, las pudimos constatar con posterioridad en la excavación del cercano poblado de cabañas de la Era de los Antiguos.

De momento no se han realizado nuevas excavaciones de concheros y, por lo tanto, no hemos podido contrastar si estas tendencias se repiten en el resto. No obstante, sí hemos realizamos prospecciones intensivas en la mitad occidental de la isla y selectivas en la otra mitad, documentando mejor la presencia de este tipo de yacimientos y, además, realizamos recientemente una revisión de las antiguas excavaciones en los concheros de Punta Llana, así como el estudio que más adelante exponemos.

Las secuencias estratigráficas de diversos yacimientos de La Palma, Tenerife y la propia Gomera (por ejemplo, los Concheros de Arguamul), habían mostrado una evolución en los porcentajes de especies y en las tallas de las conchas. Estos cambios pueden deberse a que la recolección selectiva e intensiva sobre determinada/s especie/s provocaría descensos en las poblaciones y/o una disminución en la talla de los ejemplares capturados. Por tanto, los concheros separados en el tiempo podrían acusar dichas variaciones y decidimos comprobar este extremo en Punta Llana (Navarro 1999).

Desechamos los concheros con marcados procesos postdeposicionales y elegimos los que forman un paquete compacto de caparazones ( $\mathrm{n}^{\circ} \mathrm{s} 1,2,4$ y 9), para analizar la composición específica y las tallas a partir de las evidencias del nivel superficial. No es el sistema óptimo, porque sólo registra la última fase del conchero, pero es una alternativa a las excavaciones que en las presentes circunstancias administrativas no es posible afrontar, hasta que futuras intervenciones refrenden o no la validez del método empleado. Se acotó una cuadrícula de $1 \mathrm{~m}^{2}$ en la parte central de cada conchero; en ella se contabilizó el número de ejemplares por especie que se pudieran identificar a simple vista, es decir que se apreciara el dorso de la concha, admitiendo sólo los especímenes completos o los incompletos que conservaran el ápice. De esta manera se obtuvo una estimación del número de individuos por metro cuadrado en superficie (N.I.x $1 \mathrm{~m}^{2}$ ) y, para aproximarnos más a la composición real, dividimos la cuadrícula en nueve sectores, de los que se escogió siempre el $\mathrm{n}^{\mathrm{o}} 1$. En él se procedió a retirar todos los especímenes completos y los fragmentos visibles en superficie, cualquiera que fuera su posición e incluidos los que estaban semicubiertos por el sedimento. Con ellos contabilizamos el número mínimo de individuos por especie (N.M.I.), y los fragmentos sin ápice no computables (Frags.). Nos interesaba analizar las tallas de las lapas, pero la mayoría de las conchas tenían alguna fractura y se optó por computar sólo la longitud, de forma que en las tablas indicamos la del espécimen mayor y menor (Long. máx/mín), así como la longitud media de todos los especímenes. 


\begin{tabular}{|c|c|c|c|c|c|}
\hline $\begin{array}{c}\text { Punta Llana } \\
\text { CONCHERO } 1\end{array}$ & N.I. $x 1 \mathrm{~m}^{2}$ & N.M.I. & Frags. & Long. máx / mín & Long.media \\
\hline Patella tenuis crenata & 139 & 23 & 19 & $72 / 39 \mathrm{~mm}$ & $50 \mathrm{~mm}$. \\
\hline P. ulyssiponensis aspera & 99 & 17 & 13 & $55 / 38 \mathrm{~mm}$. & $45 \mathrm{~mm}$. \\
\hline P. piperata & 12 & 2 & & & $39 \mathrm{~mm}$. \\
\hline Patella sp. & & 1 & & & \\
\hline Thais haemastoma & 8 & 1 & 1 & V & \\
\hline Osilinus atratus & 3 & & 1 & & \\
\hline $\begin{array}{c}\text { Punta Llana } \\
\text { CONCHERO } 2\end{array}$ & N.I. $x 1 \mathrm{~m}^{2}$ & N.M.I. & Frags. & Long. máx / mín & Long.media \\
\hline Patella tenuis crenata & 58 & 8 & 2 & $54 / 43 \mathrm{~mm}$. & $49 \mathrm{~mm}$. \\
\hline P. ulyssiponensis aspera & 43 & 7 & 3 & $61 / 33 \mathrm{~mm}$ & $46 \mathrm{~mm}$. \\
\hline P. piperata & 7 & 1 & & & \\
\hline Patella $s p$. & 1 & 1 & & & \\
\hline Osilinus atratus & 3 & & & & \\
\hline $\begin{array}{c}\text { Punta Llana } \\
\text { CONCHERO } 4 \\
\end{array}$ & N.I. $x 1 \mathrm{~m}^{2}$ & N.M.I. & Frags. & Long. máx / mín & Long.media \\
\hline Patella tenuis crenata & 65 & 13 & 6 & $52 / 42 \mathrm{~mm}$. & $49 \mathrm{~mm}$. \\
\hline P. ulyssiponensis aspera & 26 & 5 & 9 & $45 / 25 \mathrm{~mm}$. & $38 \mathrm{~mm}$. \\
\hline P. piperata & 5 & 1 & & & $40 \mathrm{~mm}$. \\
\hline Patella sp. & & 2 & & & \\
\hline Thais haemastoma & 7 & 1 & & & \\
\hline Osilinus atratus & 2 & & & & \\
\hline $\begin{array}{c}\text { Punta Llana } \\
\text { CONCHERO } 9 \\
\end{array}$ & N.I. $x 1 \mathbf{m}^{2}$ & N.M.I. & Frags. & Long. máx / mín & Long.media \\
\hline Patella tenuis crenata & 19 & 3 & 2 & $50 / 40 \mathrm{~mm}$. & $45 \mathrm{~mm}$. \\
\hline P. ulyssiponensis aspera & 64 & 10 & 9 & $50 / 29 \mathrm{~mm}$. & $38 \mathrm{~mm}$. \\
\hline P. piperata & 6 & 1 & & & \\
\hline Thais haemastoma & 8 & 1. & 1 & & \\
\hline Osilinus atratus & 21 & 2 & 1 & & \\
\hline Littorina striata & 2 & & & & \\
\hline Conus sp. & 1 & 1 & & & \\
\hline
\end{tabular}

Comprobamos que hay coherencia entre ambos procedimientos de conteo y que la representación interespecífica es bastante homogénea por toda la superficie. Constatamos que la densidad del conchero 1 dobla ampliamente la de los restantes, y que prácticamente coincide la composición de los concheros 1 y 2 , aproximándose también el $n^{\circ} 4$, pero el $n^{\circ} 9$ se aparta mucho de los demás. La especie mayoritaria en 1,2 y 4 es siempre la lapa de pie negro seguida de la de pie blanco, con porcentajes casi equivalentes en los 
dos primeros y aumentando algo la diferencia en el 4. Pero en el conchero 9 se invierte tajantemente la representación de ambas especies, bajando P.t.crenata a sólo el $15^{\prime} 7 \%$, mientras que P.u.aspera sube hasta el 52'9\%. Algo similar sucede con el burgado (Osilinus atratus), que en los concheros 1, 2 y 4 oscila entre el 1' $1 \%$ y el 2'7\%, mientras que en el 9 sube hasta el 17'3\%, donde únicamente se observó testimoniales muestras de burgado de sal (Littorina striata) y Conus sp. A lo que se añade que en éste hay un apreciable descenso en la tallas medias de las lapas, lo cual parece indicar una presión mayor sobre los recursos.

La explicación más aceptable para esta combinación de evidencias es que el conchero 9 se formó en época posterior a los otros tres. Esto queda reforzado por los restantes hallazgos, puesto que los concheros 1, 2 y 4 contenían cerámica aborigen mientras que en el sedimento del 9 hay abundantes fragmentos de teja árabe, algunos de cerámica común a torno de origen peninsular y loza popular canaria, todo ello fechado entre los siglos XVII y XIX d.n.e. Además, éste es el único conchero ubicado junto a la ermita de Guadalupe. Así queda confirmada la tendencia general, ya insinuada en Arguamul y la Era de los Antiguos, de que con el paso del tiempo se asiste a una progresiva disminución en las capturas de P.t.crenata, a la vez que aumenta $P$.u.aspera. Corrobora esta conclusión el material procedente de excavaciones en sitios históricos, como la Torre del Conde y la Casa de Colón, donde Osilinus atratus es mucho más frecuente que en contextos prehistóricos, además P.u.aspera predominaba claramente sobre P.t.crenata, y las tallas medias de las lapas eran inferiores a las prehistóricas.

Las implicaciones crono-culturales y la función de estas acumulaciones de conchas en las Islas Canarias han sido objeto de amplias disquisiciones. Para empezar, son frecuentes en El Hierro, La Gomera, Tenerife (Oeste y Sur de la isla) y son más raros en Fuerteventura y Lanzarote, faltando en las dos restantes. Dentro de la isla que nos ocupa, sorprende el hecho de que los concheros están siempre ubicados junto a la costa en las vertientes del Este, Norte y Oeste-Suroeste, pero faltan en el Sur, siendo así que en general es más fácil mariscar aquí que en el Norte y, por otra parte, no era una zona despoblada ni mucho menos.

Más evidencias existen respecto a su función. En casi todo el perímetro de La Gomera las costas son acantiladas o muy escarpadas, dificultando el acceso a los recursos marinos y motivando que la franja intermareal sea estrecha y que, por tanto, se restrinja la disponibilidad de este recurso. Puede que ésta sea una de las razones para que en la costa Norte los concheros se encuentren dispersos y relativamente distantes entre sí, y sólo donde los cantiles costeros se atenúan algo (como en la zona de Arguamul) se reduce la distancia entre ellos. Sin embargo, en la llanura de Punta Llana, al Este de la isla, hubo una gran concentración de concheros, de los que hoy se conservan 10; y otra densidad similar o incluso mayor existió en la gran llanura costera de Valle Gran Rey, situado al Oeste (Fig. 1). Ambos lugares reúnen unas condiciones muy parecidas que, sin duda, ayudan a explicar estas congregaciones: son costas planas a las que se accede fácilmente y donde, sobre todo, durante la bajamar quedan al descubierto vastas franjas intermareales rocosas y/o pedregosas, que son el mejor campo de marisqueo. Un caso similar se da en el litoral de Buenavista y Teno (isla de Tenerife).

No pretendemos dar una simple explicación determinista, porque opinamos que en la distribución espacial hay implicaciones de tipo social. En el Norte de la isla se constatan ciertas relaciones territoriales entre concheros y poblados estables. La mayoría están ubicados en altozanos inmediatos a la orilla del mar y separados entre sí por distancias semejantes. Cada conchero suele coincidir con uno o varios asentamientos ubicados en el mismo sector aunque a cota superior, como si reflejara una actividad local.

Entre los caparazones de moluscos suelen aparecer algunos huesos de ovicaprinos ${ }^{16}$ y peces, así como cerámica y utillaje lítico. Además, no pocas conchas muestran alteraciones térmicas y, como hemos visto, se han documentado hogares. Todo ello nos induce a pensar que allí se prepararon y consumieron sobre

16. En los Concheros de Arguamul, la mayoría son huesos de las extremidades de ovicaprinos jóvenes. 
todo alimentos derivados de la recolección marina, pero también animales domésticos. Ello obliga a considerar el papel de los concheros como punto de reunión tras las labores de marisqueo, en los que se realizaron comidas colectivas, no sabemos si consumiendo la totalidad o una parte del producto recolectado, pues son muy abundantes los restos malacológicos en viviendas. Más difícil es averiguar si los concheros generados por esta práctica adquirían una consideración simbólica especial, como se ha propuesto para la isla de El Hierro (M.C. Jiménez 1991). Nosotros sostenemos que responden a comidas grupales con un contenido social, seguramente celebradas en fechas determinadas, que deben coincidir con las épocas en que hay mayor disponibilidad de marisco y pescado y relativa facilidad para capturarlos. En las bravías costas septentrionales de Canarias eso se produce aproximadamente entre abril y octubre, con unos momentos álgidos que coinciden con las mareas largas equinocciales.

Transcurridos casi 30 años desde los trabajos de Pellicer y Acosta, las investigaciones arqueológicas en La Gomera pasan ahora por una etapa fecunda, pese al escaso apoyo de la Administración Autonómica. Se ha consolidado un equipo de trabajo que desarrolla una línea de investigación y una labor patrimonial auspiciada por el Cabildo Insular. Uno de los logros más largamente perseguidos en estas tres décadas es el Museo Arqueológico, que en breve iniciará su andadura.

\section{BIBLIOGRAFÍA}

ACOSTA MARTÍNEZ, P.; HERNÁNDEZ PÉREZ, M.S. y NAVARRO MEDEROS, J.F. (1977):

"Excavaciones arqueológicas en los concheros de Arguamul, La Gomera (Canarias)", El Museo Canario, XXXVI-XXXVII: $259-276$.

ÁLVAREZ DELGADO, J. (1947): Excavaciones arqueológicas en Tenerife (Canarias), 1944-1945. Informes y Memorias de la Comisaría general de Excavaciones Arqueológicas 14. Madrid.

BATE, L.F. (1998): El proceso de investigación en arqueología. Barcelona (Crítica).

BETHENCOURT ALFONSO, J. (1881): "Notas para los estudios prehistóricos de La Gomera y Hierro. II. El sistema religioso de los antiguos gomeros", Revista de Canarias III: 355-356, Santa Cruz de Tenerife. GONZÁLEZ ANTÓN, R. y TEJERA GASPAR, A. (1981): Los aborígenes Canarios. La Laguna. HERNÁNDEZ PÉREZ, M.S. (1982): "Consideraciones sobre el conjunto arqueológico de El Julan (El Hierro, Islas Canarias)". Instituto de Estudios Canarios. 50 aniversario: 187-223. S/C de Tenerife: Instituto de Estudios Canarios.

JIMÉNEZ GÓMEZ, M.C. (1991): "Magia y ritual en la prehistoria de El Hierro", Tabona VII: 159-172.

LORENZO PERERA, M. (1982): "El ara de sacrificio de Punta Gorda (costa de Sabinosa) y algunas consideraciones sobre economía, sociedad y vida espiritual prehispánica herreña", Homenaje a Alfonso Trujillo: 833-869, S/C de Tenerife.

NAVARRO MEDEROS, J.F. (1975): Contribución a la Carta Arqueológica de la isla de La Gomera (Canarias). Memoria de Licenciatura, Universidad de La Laguna.

- (1992): Los gomeros. Una prehistoria insular. S/C de Tenerife: Dirección General de Patrimonio Histórico.

- (1999): “Arqueología de Punta Llana y su entorno”, en G. DÍAZ et al.: La Virgen Gomera de Guadalupe. Historia de una tradición viva: 26-47. Santa Cruz de Tenerife (Cabildo Insular de La Gomera).

NAVARRO MEDEROS, J.F.; HERNÁNDEZ GÓMEZ, C.M.; ALBERTO BARROSO, V.; BORGES DOMÍNGUEZ, E.; BARRO ROIS, A. y HERNÁNDEZ MARRERO, J.C. (2000): “Aras de sacrificio y grabados rupestres en el Lomo del Piquillo (isla de La Gomera)". Estudios Canarios. Anuario del Instituto de Estudios Canarios XLIV. 
NAVARRO MEDEROS, J.F.; HERNÁNDEZ, C.; BORGES, E.; BARRO, A.; ALBERTO, V. y HERNÁNDEZ, J.C. (2001): "El diezmo a Orahan: pireos o aras de sacrificio en la prehistoria de La Gomera (Islas Canarias)", Tabona X.

NOWAK, H. (1967): "El "Sagrario de montaña" de los aborígenes de la Gomera", El Día, S/C de Tenerife, 19-XI-1967: 11 .

(1969): "Ein Bergheiligtum der Altogomerer, Fortaleza de Chipude", Raggi (Zurich) 9, no 4.

(1975): "Präehistorische steinbauten von La Palma, El Hierro, La Gomera und Tenerife, Kanarische Inseln", Almogaren V-VI: 23-33. Hallein.

PELLICER CATALÁN, M. (1969): "Panorama y perspectivas de la arqueología canaria", Revista de Historia Canaria XXXII (n's 157-164) (1968-1969): 291-302.

_ (1973): "Para qué sirvió realmente la Fortaleza de Chipude (Excavación del Departamento de Arqueología de la Universidad de La Laguna)", El Día, S/C de Tenerife, 18-XI-1973.

_ (1974): "Elementos culturales de la prehistoria canaria. Ensayo sobre orígenes y cronologías de las culturas", Miscelánea Arqueológica II: 145-161, Barcelona.

(1979): "La Fortaleza de Chipude", II Coloquio de Historia Canario-Americana (1977): 275-282, Las Palmas.

SERRA RÁFOLS, E. (1967): "El redescubrimiento de la Fortaleza de Chipude (90 años después pasé por la misma senda)", El Día, S/C de Tenerife, 29-XI-1967.

SERRA RÁFOLS, J. de C. (1945): "Excursión a los concheros de Teno, I", Revista de Historia XI ( $\left.n^{\circ} 72\right)$ : 426-432.

(1946): "Excursión a los concheros de Teno, II", Revista de Historia XII (n ${ }^{\circ}$ 73): 17-25. 


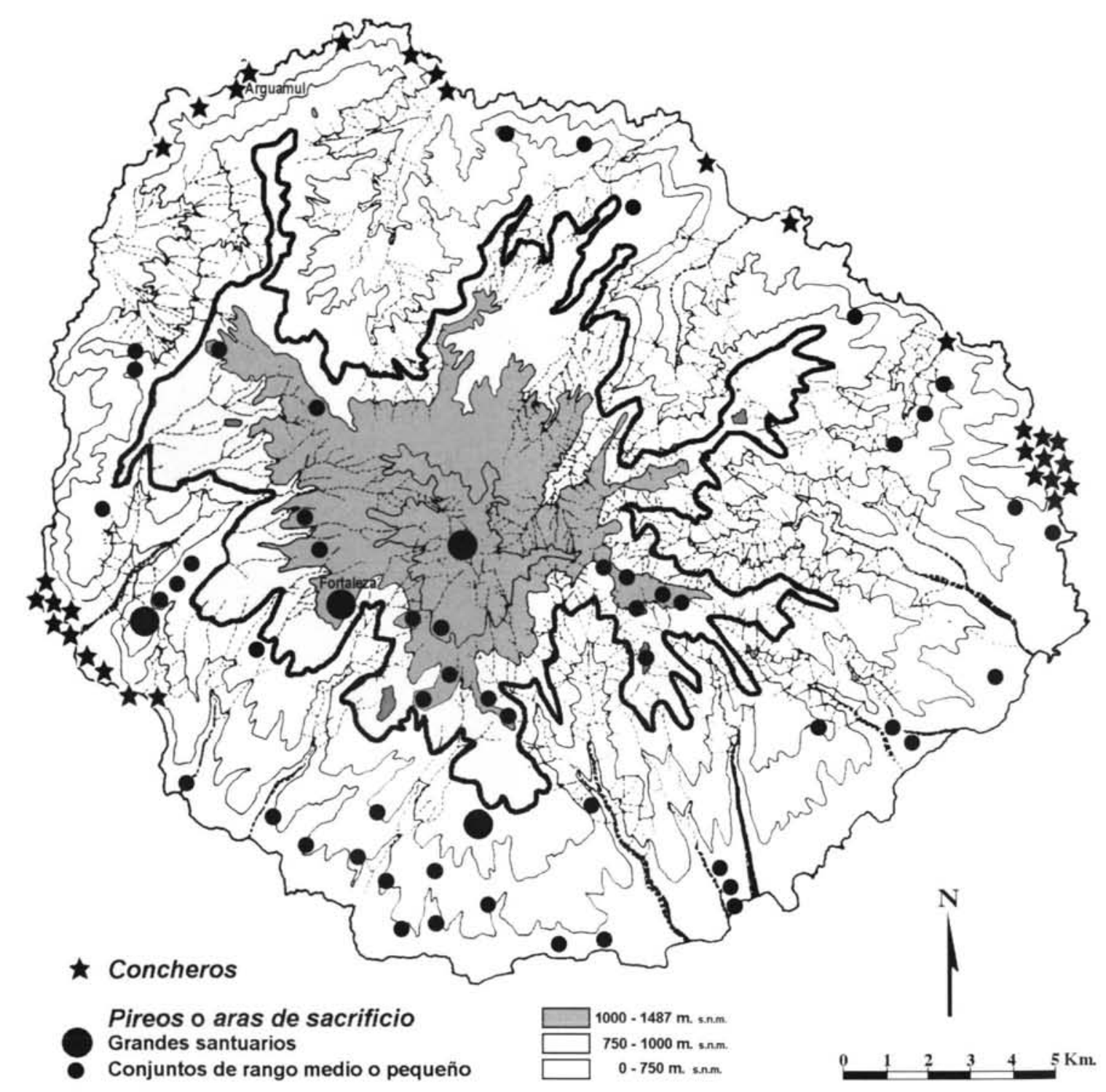

Figura 1: La Gomera: distribución de concheros y conjuntos de pireos o aras de sacrificio. 

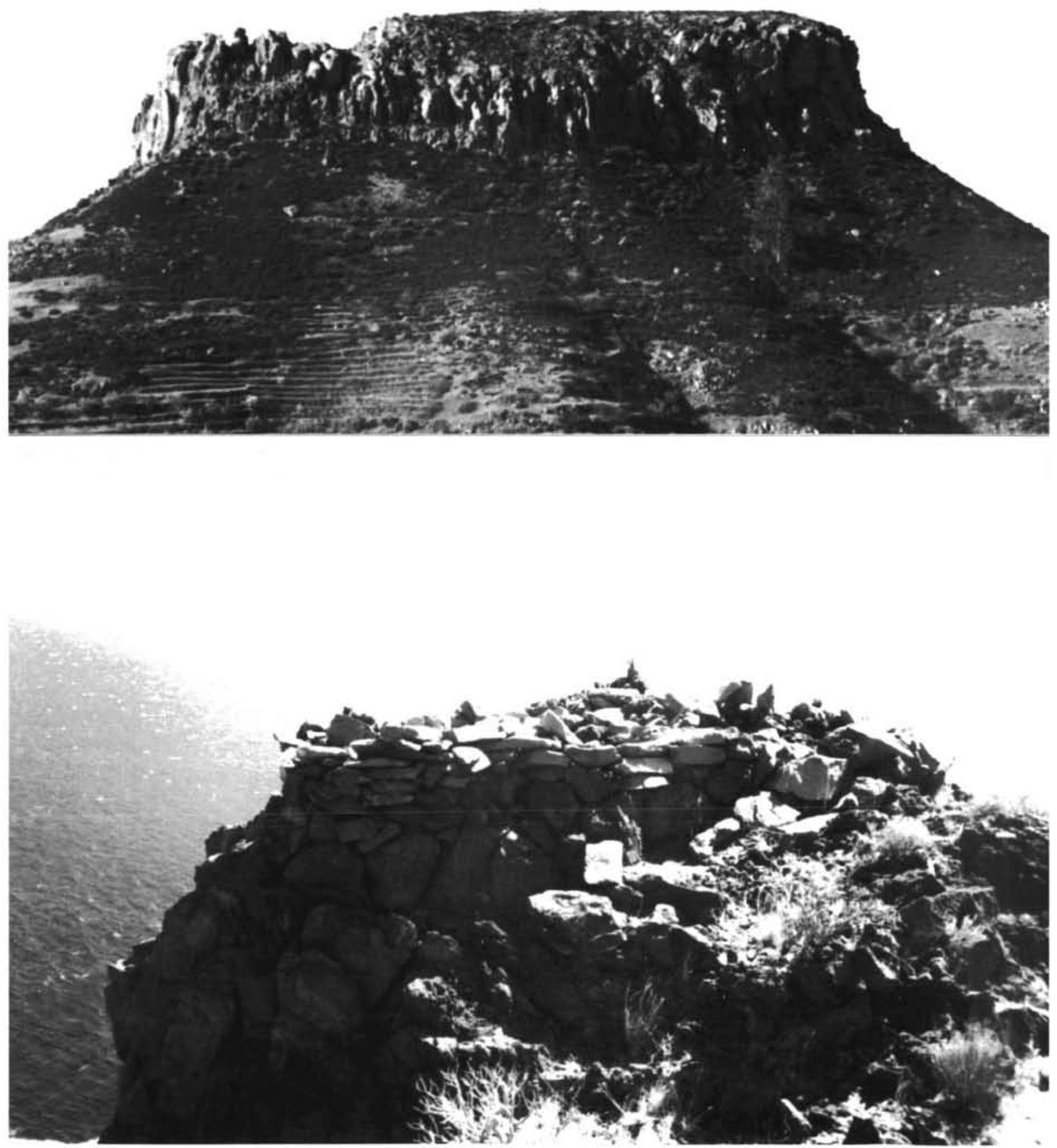

Lámina Ib: Un pireo o ara de sacrificio de estructura compleja. 